
p.712-717, jul-set 2005 .

\title{
Desempenho agronômico do bicultivo da alface em sistemas consorcia- dos com cenoura em faixa sob diferentes densidades populacionais
}

\author{
Aurélio P. Barros Júnior; Francisco Bezerra Neto; Maria Zuleide de Negreiros; Eliane Q. de Oliveira; \\ Lindomar Maria da Silveira; Maria José T. Câmara \\ ESAM, C. Postal 137, 59625-900 Mossoró-RN; E-mail: bezerra@esam.br
}

\section{RESUMO}

O experimento foi realizado de junho a setembro de 2003, em área experimental da ESAM, para avaliar o desempenho agronômico do bicultivo da alface em sistemas consorciados com cenoura em faixa sob diferentes associações de densidades populacionais. $\mathrm{O}$ delineamento experimental utilizado foi blocos casualizados completos, com cinco repetições, em esquema fatorial 4 x 4 . Os tratamentos foram resultantes da combinação de quatro populações de alface (40\%, 60\%, $80 \%$ e $100 \%$ da população recomendada no cultivo solteiro, PRCS) com quatro populações de cenoura $(40 \%, 60 \%, 80 \%$ e $100 \%$ da PRCS). A população recomendada, para o cultivo solteiro da alface foi de 250.000 plantas/ha e para cultivo da cenoura foi de 500.000 plantas/ha. As cultivares de alface e cenoura utilizadas foram, respectivamente: Tainá e Brasília. Avaliou-se na alface: altura e diâmetro das plantas, número de folhas e peso fresca por planta, peso seca da parte aérea e produtividade. Na cenoura foram avaliadas a produtividade total e comercial de raízes. Não houve interação significativa entre as densidades populacionais de alface e de cenoura em qualquer uma das características avaliadas em ambas as culturas. No primeiro cultivo, o aumento da densidade populacional da alface aumentou de modo significativo a sua produtividade, e diminuiu a altura das plantas e peso fresca por planta. Aumento na associação das densidades populacionais de ambas as culturas aumentaram o peso seco da parte aérea da alface. No segundo cultivo, o aumento da densidade populacional da alface aumentou de modo significativo a altura das plantas, sua produtividade e peso seco da parte aérea, além de diminuir seu peso fresco por planta. O aumento na associação das densidades populacionais das duas culturas aumentou a produtividade total e comercial da cenoura.

Palavras-chave: Daucus carota, Lactuca sativa, desempenho agronômico, sistemas consorciados.

\begin{abstract}
Lettuce bicropping agronomic performance in intercropping systems with carrot in a strip arrangement under different planting densities

The experiment was carried out from June to September 2003, in the field, in Mossoró, Rio Grande do Norte State, Brazil, to evaluate the lettuce bicropping agronomic performance in intercropping systems with carrot in a strip arrangement under different planting densities of component crops. The experimental design used was of randomized complete blocks in a $4 \times 4$ factorial scheme with five replications. The treatments of the factorial consisted of the combination of four lettuce-planting densities $[40 \%, 60 \%, 80 \%$ and $100 \%$ of the recommended sole crop density (RSCD)] with four carrot-planting densities (40\%, 60\%, $80 \%$ and $100 \%$ of the RSCD). The recommended planting densities for lettuce and carrot in sole crop were of 250.000 and 500.000 plants/ha, respectively. The planted lettuce and carrot cultivars were respectively: Tainá and Brasília. Evaluations of plant height and diameter, number of leaves and fresh weight per plant, shoot dry mass, and leaf productivity were made in the lettuce crop. In the carrot crop, total and commercial yields of roots were evaluated. There was no significant interaction between lettuce densities and carrot densities in any assessed trait of both crops. In the first lettuce growing, the increase of planting density increased significantly lettuce leaf yield and decreased plant height and fresh mass per plant. Increasing in the association of planting densities of both crops increased shoot dry mass of lettuce. In the second lettuce growing, the increase of planting density increased significantly plant height, leaf productivity and shoot dry mass, besides decreasing fresh mass per plant. As the association of carrot and lettuce planting densities increased, the total and commercial yield of roots increased.
\end{abstract}

Keywords: Daucus carota, Lactuca sativa, agronomic performance, intercropping systems.

(Recebido para publicação em 1 de abril de 2004 e aceito em 25 de maio de 2005)

$\mathrm{V}$ ariedades de sistemas consorciados são encontrados em todas as partes do mundo. Entretanto, a maior diversidade deles são observadas nos trópicos, especialmente em regiões onde o pequeno agricultor opera intensivamente em pequenas áreas (FRANCIS, 1976). Os sistemas consorciados envolvendo hortaliças têm-se tornado uma realidade nessas áreas, constituindo-se numa forma de produção de valor biológico, agroeconômico e nutricional
(DAVIS; WOOLLEY, 1993). A importância de muitos fatores que influenciam as decisões de manejo nesses sistemas ainda não tem sido estudada a contento e nem tem suas interações múltiplas sido quantificadas sucessivamente pela pesquisa (OLIVEIRA et al., 2003). Neste contexto, encontra-se o cultivo da alface e cenoura, hortaliças de boa expressão econômica e nutricional.

A eficiência do consórcio depende de uma variedade de fatores que vêm sendo trabalhados em pesquisas, como escolha de cultivares adaptadas ao sistema, padrão de cultivo, produção de mudas, arranjo espacial das culturas componentes, densidade de plantio, entre outros.

Costa et al. (2003), avaliando a produtividade de cultivares de alface e de rúcula, em consórcio, em relação aos seus monocultivos, verificaram que o diâmetro, peso fresco e seco de alface em monocultivo não diferiu da obtida 
em consórcio. Saldanha (2001), avaliando o desempenho de quatro cultivares de alface crespa consorciadas com cenoura cv. Brasília, em três sistemas de cultivos em Mossoró, verificou que independentemente dos sistemas testados, as maiores produtividades de alface foram registradas nas cultivares Lucy Brown e Tainá e que as cultivares de alface tiveram produções adequadas para a comercialização, em todos os sistemas testados.

Bezerra Neto et al. (2003), avaliando o rendimento e indicadores de competição do bicultivo de alfaces crespas e lisas consorciadas com dois tipos de cenoura em cultivo em faixa, observaram que as cultivares crespas tiveram melhor desempenho produtivo e exerceram menor pressão de competição na cenoura quando comparada com as cultivares de alface lisas, contribuindo assim para a maior eficiência dos sistemas consorciados. Oliveira (2003), estudando o bicultivo de alfaces americanas consorciadas com cenoura cv. Brasília em dois sistemas de cultivos em faixas na região de Mossoró, verificou que os sistemas de cultivos influenciaram o diâmetro de plantas, o peso da peso seca da parte aérea e a produtividade de alface no primeiro cultivo e estas características mais o número de folhas por planta de alface, no segundo cultivo.

As propostas de espaçamento e densidade de plantio, para as culturas em geral, têm procurado atender às necessidades específicas dos tratos culturais e a melhoria da produtividade. Todavia, alterações em espaçamento e densidade induzem uma série de modificações no crescimento e no desenvolvimento das plantas e precisam ser mais bem conhecidas (SOUZA, 1996). A fim de fornecer maiores subsídios para o desenvolvimento de sistemas consorciados sustentáveis de alface associada à cenoura, este trabalho propôs-se avaliar o desempenho agronômico do bicultivo da alface em sistemas consorciados com cenoura em faixa sob diferentes densidades populacionais das culturas componentes.

\section{MATERIAL E MÉTODOS}

O experimento foi realizado na horta da ESAM, de junho a setembro de
2003, em solo Argissolo Vermelho Amarelo Eutrófico. Amostras de solo coletadas foram processadas e analisadas no laboratório de química e fertilidade de solos da ESAM, cujos resultados foram: $\mathrm{pH}$ (água 1:2,5) =8,49; $\mathrm{Ca}$ $=7,12 \mathrm{cmol}_{\mathrm{c}} \mathrm{dm}^{-3} ; \mathrm{Mg}=4,48 \mathrm{cmol}_{\mathrm{c}} \mathrm{dm}^{-3}$; $\mathrm{K}=1,64 \mathrm{cmol}_{\mathrm{c}} \mathrm{dm}^{-3} ; \mathrm{Na}=0,24 \mathrm{cmol}$ $\mathrm{dm}^{-3} ; \mathrm{Al}=0,00 \mathrm{cmol} \mathrm{dm}^{-3}$ e $\mathrm{P}=382,7$ $\mathrm{mg} \mathrm{dm}{ }^{-3}$.

O município de Mossoró está situado a $18 \mathrm{~m}$ de altitude, a $5^{\circ} 11^{\prime}$ de latitude Sul e $37^{\circ} 20^{\prime}$ de longitude Oeste. O clima da região, de acordo com a classificação Köppen, é BSwh', isto é, seco e muito quente, com duas estações climáticas: uma seca que vai geralmente de junho a janeiro, e uma chuvosa, de fevereiro a maio.

$\mathrm{O}$ delineamento experimental utilizado foi de blocos casualizados completos com cinco repetições, sendo os tratamentos arranjados em esquema fatorial $4 \times 4$. Os tratamentos resultaram da combinação de quatro populações de plantas de alface $[40 \%, 60 \%, 80 \%$ e $100 \%$ da população recomendada no cultivo solteiro (PRCS)] com quatro populações de plantas de cenoura $(40 \%$, $60 \%, 80 \%$ e $100 \%$ da PRCS). As populações recomendadas na região para o cultivo solteiro da alface e cenoura são de 250.000 plantas/ha (SILVA, 1999) e de 500.000 plantas/ha (SIQUEIRA, 1995), respectivamente, nos espaçamentos de $0,20 \times 0,20 \mathrm{~m}$ e 0,20x0,05 m.

Cada parcela no sistema consorciado foi constituída de duas faixas (uma de cenoura e outra de alface) com quatro fileiras. A bordadura constituiu-se de uma fileira em cada lado da parcela. A área total de cada parcela foi de $2,40 \mathrm{~m}^{2}$ $(2,00 \times 1,20 \mathrm{~m})$, com uma área útil de $1,60 \mathrm{~m}^{2}(1,60 \times 1,00 \mathrm{~m})$. O espaçamento entre fileiras foi de $0,20 \mathrm{~m}$ e entre plantas dentro delas foram de 0,$10 ; 0,12$; 0,17 e $0,25 \mathrm{~m}$ para a alface e de 0,05 ; 0,$06 ; 0,08$ e $0,125 \mathrm{~m}$ para a cenoura.

A cultivar de alface utilizada no experimento foi a Tainá, indicada para o mercado de consumo fresco, devido ao excelente sabor. Caracteriza-se pela alta capacidade produtiva, boa formação de ombro e alta resistência ao pendoamento precoce (SEMENTES SAKAMA, 2002). A cultivar de cenoura foi a
Brasília, indicada para a região nordeste (VIEIRA et al.,1983).

Foi realizada uma solarização na área de plantio, durante 60 dias, para evitar ou reduzir a população de fitopatógenos do solo, que viessem prejudicar a produtividade da cultura da cenoura. Durante a condução do experimento, foram efetuadas capinas manuais e irrigação pelo sistema de microaspersão.

Nos canteiros de plantio, foram realizadas a adubação orgânica com 80 t/ ha de esterco de bovinos e a química com $40 \mathrm{~kg} / \mathrm{ha}$ de nitrogênio, na forma de uréia, $60 \mathrm{~kg} / \mathrm{ha}$ de $\mathrm{P}_{2} \mathrm{O}_{5}$, na forma de superfosfato simples e $30 \mathrm{~kg} /$ ha de $\mathrm{K}_{2} \mathrm{O}$, na forma de cloreto de potássio, de acordo com a análise realizada no solo e recomendações do IPA (IPA, 1998).

Foram realizadas duas adubações nitrogenadas em cobertura na cenoura, uma aos 25 dias após a semeadura e a outra aos 45 dias com $40 \mathrm{~kg} / \mathrm{ha}$ de nitrogênio na forma de uréia. Junto com a primeira adubação de cobertura nitrogenada, foi realizada paralelamente uma adubação potássica de $30 \mathrm{~kg} / \mathrm{ha}$ de $\mathrm{K}_{2} \mathrm{O}$.

Efetuaram-se também adubações foliares de $30 \mathrm{ml} / 20 \mathrm{ml}$ de água da formulação $14 \%$ de $\mathrm{N}, 4 \%$ de $\mathrm{P}_{2} \mathrm{O}_{5}, 6 \%$ de $\mathrm{K}_{2} \mathrm{O}, 0,8 \%$ de $\mathrm{S}, 1,5 \%$ de $\mathrm{Mg}, 2 \%$ de $\mathrm{Zn}, 1,5 \%$ de $\mathrm{Mn}, 0,1 \%$ de $\mathrm{B}$ e $0,05 \%$ de Mo, aos 25 e 30 dias após a semeadura da alface.

A alface foi semeada em dois cultivos sucessivos, em 30/05 e 08/08/2003, em copos descartáveis de $150 \mathrm{ml}$, contendo como substrato comercial uma mistura de fibra de coco e composto orgânico na proporção de 1:2. Foram semeadas de três a cinco sementes por recipiente e aos três dias após a emergência efetuou-se o primeiro desbaste, deixando-se duas plântulas/recipiente, e aos oito dias o segundo desbaste, deixando-se apenas uma plântula/recipiente. As mudas foram produzidas sob sombreamento, utilizando-se uma estufa coberta com plástico branco leitoso. As mudas de alface do primeiro cultivo foram transplantadas para as faixas adjacentes da cenoura aos 24 dias após a semeadura e as do segundo cultivo aos 18 dias após a semeadura, quando a cenoura se encontrava com 11 e 75 dias 

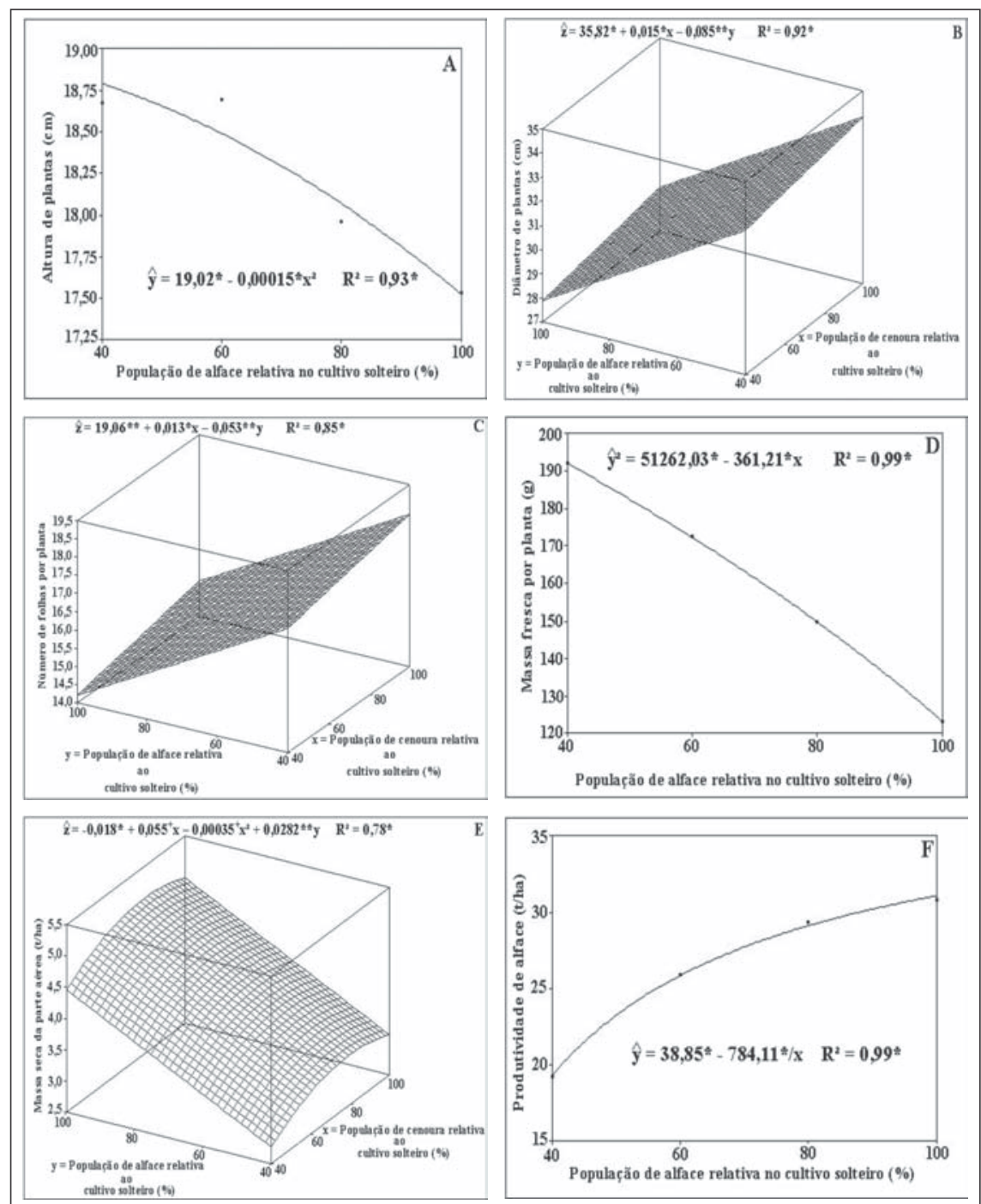

Figura 1. Altura e diâmetro de planta $(\mathrm{cm})$, número de folhas por planta, peso fresco por planta $(\mathrm{g})$, peso seco da parte aérea $(\mathrm{t} / \mathrm{ha})$ e produtividade de alface $(\mathrm{t} / \mathrm{ha})$ no primeiro cultivo em função de diferentes densidades populacionais de alface e cenoura em sistema consorciado. Mossoró, ESAM, 2003.

da semeadura, respectivamente. A cenoura, cultura principal, foi semeada em $12 / 06 / 2003$. O desbaste foi realizado 25 dias após a semeadura, deixando-se por metro linear o número de plantas do nível populacional testado.

A colheita da alface no primeiro cultivo foi realizada nos dias 21 e 22/06/ 2003, estando a cultura da cenoura aos 39 dias da semeadura e a alface aos $52 \mathrm{e}$ 53 dias da semeadura. No segundo cultivo, a colheita foi realizada nos dias 18 e 19/09/2003, aos 41 e 42 dias da semeadura. A colheita da cenoura foi realizada em 08/09/2003, aos 88 dias após a sua semeadura, estando a alface do segundo cultivo com 13 dias após o transplantio.
As características avaliadas na alface foram altura e diâmetro das plantas, número de folhas por planta, peso fresco por planta, peso seco e fresco da parte aérea (produtividade) e na cenoura foram as produtividades total e comercial de raízes.

Uma análise de variância univariada para o delineamento de blocos casualizados em esquema fatorial foi utilizada para avaliar as características da alface e da cenoura. $\mathrm{O}$ software utilizado para análise foi o SPSS/PC (NORUSIS, 1990). Os efeitos dos fatores densidades populacionais foram avaliados pelos procedimentos de ajustamento de curvas de resposta através do software Table Curve Package (JANDEL SCIENTIFIC, 1991).

\section{RESULTADOS E DISCUSSÃO}

\section{Primeiro cultivo da alface}

Não houve interação significativa entre as populações de alface e de cenoura em todas as características avaliadas na alface no primeiro cultivo. Porém, houve efeito significativo apenas da população de alface na altura das plantas, na peso fresca por planta e na sua produtividade (Figuras 1A, 1D e 1F) e de ambas populações isoladamente no diâmetro das plantas, número de folhas por planta e peso seca da parte aérea (Figuras 1B, 1C e 1E). Foi tentado um ajustamento de uma regressão simples ou de uma superfície de resposta em função das densidades populacionais estudadas em cada cultura.

Para altura das plantas de alface, foi observado um comportamento decrescente desta variável com o aumento da densidade populacional de alface (Figura 1A), correspondendo a um decréscimo de $6,8 \%$. Esse comportamento se deve presumivelmente a maior competição intraespecífica em face do aumento da densidade populacional, produzindo assim, plantas de alface mais baixas nas maiores densidades.

Com relação ao diâmetro das plantas e número de folhas por planta, uma superfície de resposta linear foi obtida em função das densidades populacionais da alface e da cenoura (Figuras 1B e 1C). A combinação das densidades de $40 \%$ da PRCS de alface com $100 \%$ da PRCS de cenoura proporcionaram os valores máximos de 33,92 cm para o diâmetro de plantas e de 18 , para o número de folhas por planta de alface, respectivamente. Estes resultados numa população baixa de alface e alta da cenoura são completamente previsíveis, pois quando estas variáveis foram determinadas a cenoura estava a menos da metade de seu ciclo, período este, onde a competição interespecifica não era tão forte. Eles concordam em parte com os obtidos por Silva (1999), estudando cultivares de alface em diferentes espaçamentos sob temperatura e luminosidade elevadas, que concluiu que uma menor densidade populacional de alface, proporciona menor competição intraespecífica, conseqüentemente maior diâmetro de plantas e número de folhas por planta. 
O peso fresco por planta decresceu com o aumento da população de alface (Figura D), correspondendo a um decréscimo de $35,9 \%$. Esse comportamento se deve a maior competição intraespecífica em face do aumento da densidade populacional, produzindo assim, menor quantidade de peso fresco por planta de alface nas maiores densidades.

Para peso seco da parte aérea, foi ajustada uma superfície de resposta em função das densidades de alface e de cenoura (Figura 1E). Esta variável teve um comportamento quadrático em função do aumento da população de cenoura e linear crescente em função do aumento da população de alface. A combinação das densidades de $100 \%$ da PRCS de alface com 78,87\% da PRCS de cenoura proporcionou o valor máximo de 4,96 t/ha para peso seco da parte aérea. Infere-se desta alta combinação de densidades, que a pressão de competição intraespecifica não foi tão forte já que a competição interespecífica praticamente foi inexpressiva. Comportamento diferente foi observado por Janick (1968), que relata que a competição intraespecífica, causada pela pressão populacional das densidades de alface resultou em uma maior competição pelos recursos ambientais, provocando uma redução do peso seco da parte aérea, devido ao aumento da densidade populacional de plantas por unidade de área.

A produtividade de alface (ou peso fresco da parte aérea) cresceu com o aumento na sua população, atingindo o valor de $31 \mathrm{t} /$ ha na população de alface de $100 \%$ da PRCS (Figura 1F), correspondendo a um crescimento da ordem de $61,1 \%$. Isto significa dizer que, neste sistema de plantio, a máxima produtividade de alface seria alcançada numa população superior à recomendada no cultivo solteiro, devido em parte a uma inexpressiva competição interespecífica, causada pela cenoura em estágio vegetativo (estágio onde ocorre o crescimento primário, ou seja, o crescimento vertical das raízes) e uma baixa competição intraespecífica quando comparada a do sistema solteiro. O comportamento da produtividade foi influenciado diretamente pelo maior número de plantas por área explorada da cultura. Este resultado se assemelha aos obtidos
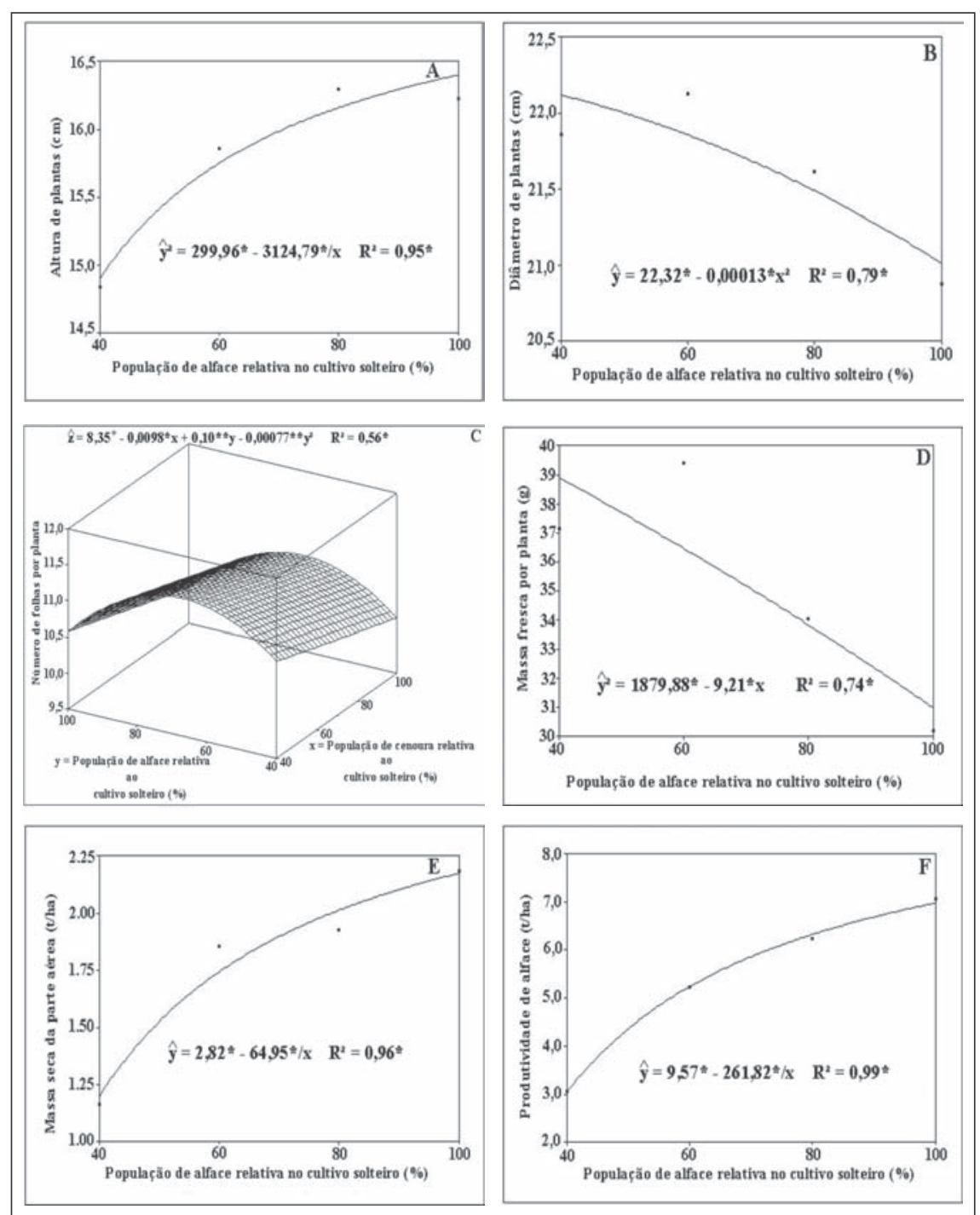

Figura 2. Altura e diâmetro de planta $(\mathrm{cm})$, número de folhas por planta, peso fresco por planta ( $\mathrm{g}$ ), peso seco da parte aérea ( $\mathrm{t} / \mathrm{ha}$ ) e produtividade de alface ( $\mathrm{t} / \mathrm{ha}$ ) no segundo cultivo em função de diferentes densidades populacionais de alface e cenoura em sistema consorciado. Mossoró-RN, ESAM, 2003.

por Silva (1999), que concluiu que as maiores densidades populacionais aumentavam o peso seco da parte aérea e a produtividade da alface, devido ao maior número de plantas por unidade de área.

\section{Segundo cultivo da alface}

Também não se observou interação significativa entre as populações de alface e de cenoura em todas as características avaliadas na alface no segundo cultivo. Porém, houve efeito significativo da população de alface na altura e diâmetro das plantas, peso fresco por planta, peso seco da parte aérea e produtividade de alface (Figuras 2A, 2B, $2 \mathrm{D}, 2 \mathrm{E}$ e $2 \mathrm{~F}$ ) e de ambas populações isoladamente apenas no número de folhas por planta (Figura 2C). Foi tentado um ajustamento de uma regressão simples ou de uma superfície de resposta em função das densidades populacionais estudadas em cada cultura.

Para altura de planta foi observado um comportamento inverso ao do primeiro cultivo, onde a altura aumentou com o aumento da densidade populacional de alface (Figura 2A). Este incremento foi cerca de $10 \%$. Esta diferença de comportamento observada entre os dois cultivos pode ser explicada teoricamente pela maior competição interespecífica causada pela cenoura, principalmente por luz e nutrientes, já 


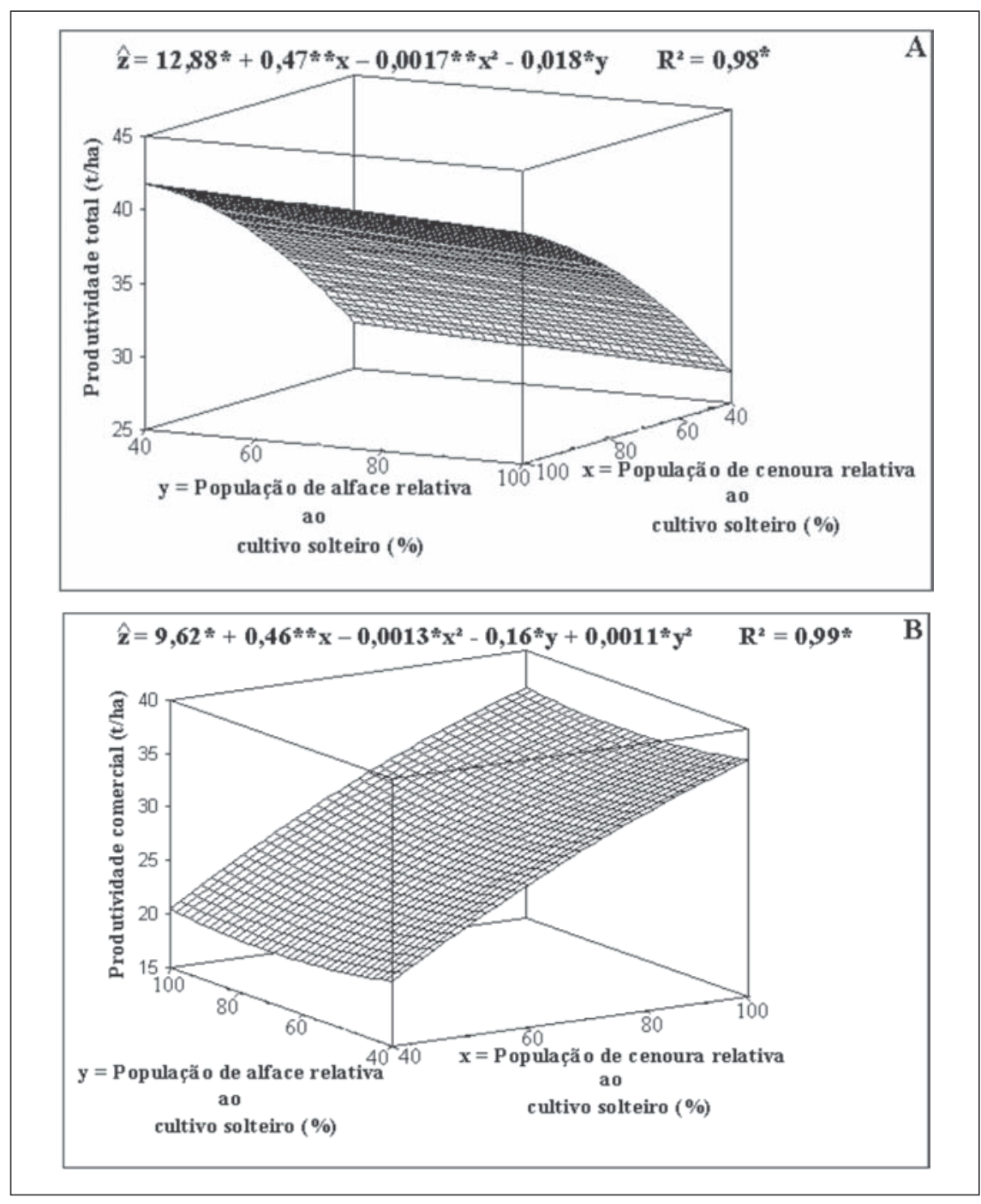

Figura 3. Produtividade total e comercial (t/ha) de diferentes densidades populacionais de cenoura e alface em sistema consorciado. Mossoró-RN, ESAM, 2003.

que nessa fase a cultura da cenoura estava aos 75 dias de seu ciclo, ou seja, em intensa competição. De acordo com Gangnebin e Bonnet (1979), em densidades populacionais mais elevadas, ocorre maior competição por luz, o que contribui para que as plantas atinjam alturas mais elevadas. Silva (1999) também observou esse comportamento, afirmando que à medida que se aumentou a densidade populacional da alface, ocorreu maior competição pelos recursos ambientais, principalmente luz, resultando em maior crescimento da cultura. $\mathrm{O}$ diâmetro das plantas e o peso fresco por planta de alface decresceram com o aumento de sua população (Figuras 2B e 2D). Este decréscimo foi cerca de $5 \%$ e $20,3 \%$, respectivamente, presumivelmente devido a maior com- le obtido no primeiro cultivo, e este se deve principalmente a maior competição intraespecífica.

As características peso seco da parte aérea e produtividade de alface aumentaram com o aumento da população de alface, atingindo o máximo na densidade de $100 \%$ da PRCS (Figuras 2E e 2F). Estes incrementos foram de $80,8 \%$ e $130 \%$, respectivamente. Foi observado também este comportamento no primeiro cultivo, onde uma redução na produção individual das plantas causada pelo maior número de plantas por hectare, foi compensada pelo aumento no rendimento por área. Significa dizer que, a quantidade máxima de peso seco da parte aérea e a máxima produtividade de alface seriam alcançada numa população superior à recomendada no cultivo solteiro. Isto se deve presumivelmente em parte a uma baixa competição interespecífica, oriunda do próprio sistema de consórcio de alface e cenoura. Estes resultados concordam com os obtidos por Silva (1999), que concluiu que as maiores densidades populacionais aumentavam o peso seco da parte aérea e a produtividade da alface, devido ao maior número de plantas por unidade de área.

\section{Cultivo da cenoura}

Não houve interação significativa entre as populações de cenoura e de alface na produtividade total e comercial de raízes da cenoura (Figuras 3A e 3B). Porém, foi observado efeito significativo das densidades populacionais das duas hortaliças nestas variáveis. Uma superfície de resposta foi ajustada em função dessas densidades populacionais das culturas componentes.

Um comportamento quadrático foi registrado na produtividade total em função do aumento da população de cenoura e um linear em função do aumento da população de alface, atingindo o valor de 40,72 t/ha na combinação de $100 \%$ PRCS de cenoura e $100 \%$ PRCS de alface. Para a produtividade comercial também foi observado um comportamento quadrático em função das populações de ambas as culturas, atingindo o valor máximo de 37,62 t/ha na combinação de $100 \%$ PRCS de cenoura e $40 \%$ PRCS de alface. Esta maior produtividade total e comercial da cenoura 
está diretamente relacionada ao maior número de plantas por área, à medida que se aumentou a densidade populacional da cenoura. Estes resultados se assemelham aos encontrados por Minami e Demétrio (1978) em cultivo solteiro, onde eles afirmaram que a causa do aumento na produtividade total $\mathrm{e}$ comercial da cenoura em relação ao aumento da densidade populacional da mesma foi resultante do maior número de plantas por área de solo. Siqueira (1995), estudando o espaçamento de plantio na produção de cenoura 'Brasília' em cultivo solteiro, no município de Mossoró verificou o mesmo comportamento.

De maneira geral, pode-se concluir que, não houve interação significativa entre as densidades populacionais de alface e de cenoura em qualquer uma das características avaliadas em ambas as culturas. No primeiro cultivo, o aumento da densidade populacional da alface aumentou de modo significativo a sua produtividade, e diminuiu a altura das plantas e peso fresco por planta. Aumento na associação das densidades populacionais de ambas as culturas aumentaram o peso seco da parte aérea da alface. No segundo cultivo, o aumento da densidade populacional da alface aumentou de modo significativo a altura das plantas, sua produtividade e peso seco da parte aérea, além de diminuir seu peso fresco por planta. $\mathrm{O}$ aumento na associação das densidades populacionais das duas culturas aumentou a produtividade total e comercial da cenoura.

\section{LITERATURA CITADA}

BEZERRA NETO, F.; OLIVEIRA, E.Q.; NEGREIROS, M.Z. Rendimento e indicadores de competição do bicultivo de dois grupos de alfaces crespa e lisa consorciados com dois tipos de cenoura em cultivo em faixa. Horticultura Brasileira, Brasília, julho 2003. Disponível em: <http:/ /horticiencia.com.br/anais $>$. Acesso em: 20 jan. 2003. Trabalho apresentado no $43^{\circ}$ Congresso Brasileiro de Olericultura, 2003.

COSTA, C.C.; CECILIO FILHO, A.B.; GRANGEIRO, L.C. Produtividade de cultivares de alface em função da época de estabelecimento do consórcio com rúcula, no outono-inverno de Jaboticabal-SP. Horticultura Brasileira, Brasília, julho 2003. Disponível em: <http:// horticiencia.com.br/anais $>$. Acesso em: 20 jan. 2003. Trabalho apresentado no $43^{\circ}$ Congresso Brasileiro de Olericultura, 2003.

DAVIS, J.H.C.; WOOLLEY, J.N. Genotypic requirement for intercropping. Field Crops Research, Amsterdam, v.34, n.3/4, p.407-430, 1993

EMPRESA PERNAMBUCANA DE PESQUISA AGROPECUÁRIA - IPA. Recomendações de adubação para o estado de Pernambuco $\left(2^{\mathrm{a}}\right.$ aproximação). $2^{\mathrm{a}}$ ed. Rev. Recife: IPA, 1998. 198 p.

FRANCIS, C.A. Distribution and importance of multiple cropping. In: Ed. FRANCIS, C.A. (Ed.) Multiple Cropping, New York: Macmillan, 1986. p.1-19

GANGNEBIN, F.; BONNET, J. C. Some effects of spacing on the growth and development of lettuce. Horticultural Abstracts, Lullier: Switzerland, v.49, n.7, p.121-130, 1979.

IPA - Empresa Pernambucana de Pesquisa Agropecuária. Recomendações de adubação para o estado de Pernambuco: $2^{a}$ aproximação. 2 . ed. Ver. Recife: IPA, 1998. 198 p.
JANDEL SCIENTIFIC. Table Curve: curve fitting software. Corte Madera, CA: Jandel Scientific, 1991. $280 \mathrm{p}$.

JANICK, J. A ciência da horticultura. São Paulo: Livraria Freitas Bastos S. A., 1968. 485 p.

NORUSIS, M.J. SPSS/PC Statistics. Illinois: SPSS Inc., $1990.320 \mathrm{p}$.

OLIVEIRA, A.M. Bicultivo de alfaces americanas consorciadas com cenoura em dois sistemas de cultivos em faixas. 2003. 34 f. Dissertação (Mestrado em Fitotecnia) - Escola Superior de Agricultura de Mossoró, Mossoró.

OLIVEIRA, A.M.; BEZERRA NETO, F.; NEGREIROS, M.Z.; OLIVEIRA, E.Q.; GONDIM, A.R.O.; PORTO, D.R.Q.; FREITAS, K.K.C. Desempenho de cultivares de alface americana em consorciação com cenoura no primeiro cultivo em dois sistemas de cultivo em faixa. Horticultura Brasileira, Brasília, v.21, n.2, julho-2003, Suplemento-CD.

SALDANHA, T.R.F.C. Cultivares de alface crespa em sistemas solteiro e consorciado com cenoura. 2001. $41 \mathrm{f}$. Monografia (Trabalho de graduação em agronomia) - Escola Superior de Agronomia de Mossoró, Mossoró.

SEMENTES SAKAMA. Características de cultivares de alface. São Paulo: Sementes Sakama, 2002. 2 p. (Mimeografado).

SILVA, V.F. Cultivares de alface em diferentes espaçamentos sob temperatura e luminosidade elevadas na região de Mossoró-RN. 1999. 25 f. Dissertação (Mestrado em Fitotecnia) - Escola Superior de Agronomia de Mossoró, Mossoró.

SIQUEIRA, G.A.S. Espaçamentos de plantio na produção de cenoura "Brasília", no município de Mossoró-RN. 1995. 23 f. Monografia (Trabalho de Graduação em Agronomia) - Escola Superior de Agronomia de Mossoró, Mossoró.

SOUZA, L.C. Componentes de produção do cultivar de algodoeiro CNPA7H em diferentes populações de plantas. 1996. $71 \mathrm{f}$. Tese (Doutorado em Fitotecnia) - Unversidade Federal de Viçosa, Viçosa.

VIEIRA, J.V.; VECCHIA, P.T.D.; IKUTA, H. Cenoura Brasília. Horticultura Brasileira, Brasília, v.1, n.2, p.42, 1983. 